\title{
Local application of rapamycin reduces epidural fibrosis after laminectomy via inhibiting fibroblast proliferation and prompting apoptosis
}

Yu Sun ${ }^{1,3+}$, Shuai Zhao ${ }^{1,2,3 \dagger}$, Xiaolei Li $i^{1,2,3}$, Lianqi Yan ${ }^{1,2,3^{*}}$, Jingcheng Wang ${ }^{1,2,3^{*}}$, Daxin Wang ${ }^{1,3}$, Hui Chen ${ }^{1,3}$, Jihang Dai ${ }^{1,3}$ and Jun $\mathrm{He}^{1,3}$

\begin{abstract}
Background: Epidural fibrosis is a common complication after laminectomy. It is associated with intractable lower back pain and additional complications. To date, no study has evaluated whether the local application of rapamycin (RAPA) can inhibit fibroblast proliferation and reduce epidural scar adhesion after laminectomy. The results of the present study showed that the local application of RAPA reduces epidural fibrosis after laminectomy in rats.

Methods: In this study, 32 male Sprague-Dawley rats were randomly divided into four groups $(0.2 \mathrm{mg} / \mathrm{ml}$ RAPA-treated group, $0.1 \mathrm{mg} / \mathrm{ml}$ RAPA-treated group, $0.05 \mathrm{mg} / \mathrm{ml}$ RAPA-treated group and physiological saline group). Laminectomy was performed at the level of lumbar segment 1 to 2, and different concentrations of RAPA or saline were applied to the laminectomy sites for $10 \mathrm{~min}$. Four weeks after laminectomy, the rats were sacrificed, and the degrees of epidural adhesion in each group were evaluated. Macroscopic assessment, analysis of hydroxyproline content, and histological analysis were used to determine the therapeutic effect of the local application of RAPA on the inhibition of fibroblast proliferation and the reduction of epidural fibrosis after laminectomy. Next, we cultured fibroblasts from epidural scar tissues of rats that had undergone laminectomy. Fibroblasts were exposed to the indicated concentrations of RAPA, and western blotting and TUNEL assays were used to assess the effects of RAPA on inhibiting fibroblasts proliferation and promoting fibroblast apoptosis.
\end{abstract}

Results: The results of macroscopic assessments, analysis of hydroxyproline content, and histological analyses indicated that RAPA significantly inhibited fibroblast proliferation and reduced epidural fibrosis in the treated groups in the rat model. The western blotting results indicated that the expression levels of the pro-apoptotic proteins cleaved-PARP and Bax were up-regulated, whereas those of BCl-2 were reduced. TUNEL assay indicated that the apoptosis rates of fibroblasts were significantly increased after exposure to the indicated concentrations of RAPA.

Conclusions: The local application of RAPA reduced epidural fibrosis after laminectomy by inhibiting the proliferation of fibroblasts, stimulating their apoptosis, and decreasing collagen synthesis. This protocol may be used in new clinical treatment strategies to reduce epidural fibrosis after laminectomy.

Keywords: Rapamycin, Epidural fibrosis, Laminectomy, Fibroblast, Apoptosis, Proliferation

\footnotetext{
* Correspondence: yanlianqi@126.com; jingchengwyz@163.com

${ }^{\dagger}$ Equal contributors

${ }^{1}$ Department of Orthopedics, Clinical medical college of Yangzhou University,

Nantong West Road 98, Yangzhou, Jiangsu 225001, China

Full list of author information is available at the end of the article
} 


\section{Background}

Extensive epidural fibrosis is a troublesome complication after laminectomy. It can cause various clinical conditions, such as failed back pain surgery syndrome (FBSS), which is characterized by chronic radicular nerve or lower back pain [1-3]. These types of complications make revision surgeries more complex and time-consuming, and the results of reoperation are often poor $[4,5]$. Therefore, a solution to this problem is greatly needed.

Many studies have explored ways to prevent epidural scar adhesion after laminectomy. Many types of biological and synthetic materials, such as polymethyl methacrylate, polylactic acid, autologous leather, silastic silicone, and fat grafts, have shown anti-fibrotic effects [6-10]. Pharmaceutical agents, such as mitomycin C, hydroxycamptothecine, colchicine, steroid hormone and anti-inflammatory agents, have been used to reduce epidural fibrosis [11-14]. However, limited or variable success has been achieved, and some medicines cause side effects such as wound infection. Therefore, it is still clinically urgent to explore new methods for reducing epidural fibrosis. Recently, it has been reported that macrolide antibiotics, such as azithromycin and tacrolimus (FK506), exhibit effectiveness in reducing the fibrosis of epidural scars $[13,15]$.

RAPA, also called sirolimus, is a type of macrolide antibiotic and immunosuppressive agent [16-18]. Animal studies and clinical trials have shown that it has low renal toxicity and good effectiveness. It is widely used to prevent transplantation rejection $[19,20]$. Many studies have indicated that RAPA is effective in inhibiting scar adhesion. In ophthalmology, the local application of RAPA is used to prevent scar adhesion after cataract surgery [21-24]. Studies on pathological scars have indicated that RAPA inhibits the proliferation of fibroblasts [25-27]. However, no study has determined whether the local application of RAPA can reduce epidural fibrosis after laminectomy.

In the present study, we sought to evaluate the therapeutic effect of local application of RAPA on inhibiting fibroblast proliferation and reducing epidural fibrosis. The results of this study may provide a novel method to reduce the adhesion of epidural scars, which may be useful in future human trials for clinical applications.

\section{Methods}

\section{Animals, cells and reagents}

Thirty-two healthy male Sprague-Dawley rats (mean weight of $350 \mathrm{~g}$ ) were purchased from Shanghai Laboratory Animal Center. The animals received care in compliance with the principles of International Laboratory Animal Care, and the experimental protocol was approved by the Animal Care and Research Committee of
Yang Zhou University (Yangzhou, China). RAPA, which was purchased from Astellas Ireland Co, Ltd. (Killorhlin, Co. Kerry, Ireland), was dissolved in dimethyl sulfoxide (DMSO) purchased from Sigma-Aldrich (St Louis, MO, USA) and stored at $-20{ }^{\circ} \mathrm{C}$. The RAPA solution was diluted with saline or cell culture medium such that the DMSO comprised <0.1\%. Specific antibodies against cleaved-PARP, Bcl-2 and Bax were purchased from Cell Signaling Technology (Cambridge, MA, USA). All rats were randomly divided into four groups (eight rats in each group): $0.05 \mathrm{mg} / \mathrm{ml}$ RAPA, $0.1 \mathrm{mg} / \mathrm{ml}$ RAPA, $0.2 \mathrm{mg} / \mathrm{ml} \mathrm{RAPA}$, and saline groups. Before the experiment, the rats were housed for 1 week and allowed to adapt to the conditions of the laboratory.

A primary fibroblast cell line was cultured from the epidural scar tissue of rats that had undergone laminectomies. Briefly, the scar tissues at L1-L2 level were anatomically separated and rinsed immediately with phosphate-buffered saline, then cut into $1 \times 1 \mathrm{~mm}^{2} \mathrm{sec}$ tions and cultured in Dulbecco's modified Eagle's medium (DMEM; Invitrogen, CA, USA) supplemented with $10 \%$ foetal bovine serum, $0.1 \mathrm{U} / 1$ penicillin, and $50 \mu \mathrm{g} / \mathrm{ml}$ streptomycin (Gibco, CA, USA) at $37{ }^{\circ} \mathrm{C}$ in $5 \% \mathrm{CO}_{2}$. Culture media were replaced every 2 days until fibroblasts reached approximately $80 \%$ confluence. The cells of passages 3 to 6 were used in all experiments, the cells were transfered into a serum-free medium overnight and then subjected to various reagent treatments with varying doses of RAPA, as indicated in the figure legends.

All other reagents were purchased from Sigma Aldrich (St Louis, MO, USA) unless stated otherwise.

\section{Construction of the laminectomy model}

A rat laminectomy model was used to determine the effects of RAPA on epidural fibrosis. Briefly, each rat was anaesthetized with an intraperitoneal injection of $1 \%$ pentobarbital sodium solution ( $4 \mathrm{ml} / \mathrm{kg}$ body weight) and then fixed in the prone position. The animal's back hair at the level of L1 and L2 was shaved, and skin was sterilized with iodophor three times. The laminectomy model was constructed according to methods described in previous studies [28, 29]. All procedures were performed under sterile conditions with basic surgical tools, surgical microscopes and an electrical drill. A median incision of the dorsal skin at the level of L1-L2 was made, and the paraspinal muscles were separated. A rongeur was used to remove the spinous process and vertebral plate, and the dura mater at the L1 to L2 level was exposed. Then, cotton soaked with different concentrations of RAPA $(0.05 \mathrm{mg} / \mathrm{ml}, 0.1 \mathrm{mg} / \mathrm{ml}$ and $0.2 \mathrm{mg} / \mathrm{ml})$ or saline was applied to the surgical site for $10 \mathrm{~min}$ (the volume of application was approximately $1 \mathrm{ml}$ ). The surrounding tissues were protected from contact with 
the agent. Satisfactory haemostasis was achieved by using gauze; bone wax and cauterization after laminectomy were not needed. All procedures were performed with care to avoid injury to the neural tissues.

\section{Macroscopic assessment of epidural fibrosis}

Four weeks after the surgery, four rats in each group were randomly selected, and the surgical sites were reopened carefully. The degree of epidural fibrosis at the L1 to L2 level was evaluated by three professional blinded pathologists according to the Rydell classification [30] (grade $0=$ epidural scar tissue was not adherent to the dura mater; grade $1=$ epidural scar tissue was adherent to the dura mater but was easily dissected; grade $2=$ epidural scar tissue was adherent to the dura mater and was difficult to dissect without disrupting the dura mater; and grade $3=$ epidural scar tissue was firmly adherent to the dura mater and could not be dissected).

\section{Hydroxyproline content analysis}

After macroscopic assessment of epidural fibrosis, the scar tissue (wet weight = approximately $4 \mathrm{mg}$ ) was collected from L1 to L2 area surrounding the laminectomy site. The content of hydroxyproline in the scar tissue of different groups was determined according to the methods described in previous study [31, 32]. Briefly, the samples were lyophilized, ground and hydrolysed with $6 \mathrm{~mol} / \mathrm{l} \mathrm{HCl}$ at $130{ }^{\circ} \mathrm{C}$ for $12 \mathrm{~h}$ separately. The samples were then neutralized with $2.5 \mathrm{~N} \mathrm{NaOH}$ with methyl red as an indicator. Chloramine $\mathrm{T}(1 \mathrm{ml})$ was added to the hydrolysed samples along with four hydroxyproline standards of known concentrations. After incubation for $20 \mathrm{~min}$ at room temperature, the hydroxyproline developer was added to the samples and standards. The absorbance of the solution was measured at $558 \mathrm{~nm}$ with a spectrophotometer, and the hydroxyproline content per milligram of scar tissue was calculated according to the standard curve, which was constructed with serial concentrations of commercial hydroxyproline.

\section{Histological analysis}

Four rats randomly selected from each group were sacrificed after 4 weeks for histological evaluation. The entire L1-L2 spine column, including the paraspinal muscles and epidural scar tissues, was collected and immersed in $10 \%$ buffered formalin for 5 days. The specimens were decalcified in 10 \% EDTA (Sigma Aldrich, St Louis, MO, USA) for 3 weeks and embedded in paraffin. Then, 4$\mathrm{mm}$ transverse sections were made through the L1-L2 vertebra, and this was followed by staining with haematoxylin-eosin (HE) and Masson's trichrome. Three counting areas $(100 \times 100 \mu \mathrm{m}$ each $)$ were selected at the middle and at the margins of the laminectomy sites, and the number of fibroblasts was calculated.

\section{Analysis of RAPA's influence on the proliferation of fibroblasts}

To further determine the effects of RAPA on the proliferation of fibroblasts, the fibroblasts were cultured in Dulbecco's modified Eagle's medium (DMEM; Invitrogen, CA, USA) supplemented with $10 \%$ foetal bovine serum, $0.1 \mathrm{U} / \mathrm{l}$ penicillin, and $50 \mu \mathrm{g} / \mathrm{ml}$ streptomycin (Gibco, CA, USA) at $37{ }^{\circ} \mathrm{C}$ and $5 \% \mathrm{CO}_{2}$. Briefly, fibroblasts were plated in six-well plates at a density of $8 \times 10^{5}$ cells/well and cultured in Dulbecco's modified Eagle's medium (DMEM; Invitrogen, CA, USA) supplemented with $10 \%$ foetal bovine serum, $0.1 \mathrm{U} / \mathrm{l}$ penicillin, and $50 \mu \mathrm{g} / \mathrm{ml}$ streptomycin (Gibco, CA, USA) at $37{ }^{\circ} \mathrm{C}$ in $5 \%$ $\mathrm{CO}_{2}$. After reaching approximately $80 \%$ confluence, the cells were transferred into serum-free medium overnight and then subjected to treatment with different concentrations of RAPA $(0,0.01,0.1$, and $1 \mu \mathrm{g} / \mathrm{ml})$ for $48 \mathrm{~h}$, as indicated in the figure legends. Then, the number of fibroblasts and changes in cell morphology were observed under a light microscope.

\section{Western blotting analysis of apoptosis markers}

To further determine the effect of RAPA on the expression of apoptotic proteins, such as cleaved-PARP, Bax, and Bcl-2, fibroblasts were seeded in six-well plates at a density of $5 \times 10^{5}$ and cultured in DMEM supplemented with $10 \%$ foetal bovine serum and $1 \%$ penicillin. When the cells were confluent, they were transfered into serum-free medium overnight and then pre-treated with or without different concentrations of RAPA for $48 \mathrm{~h}$. Then, total proteins were extracted from cultured cells using radioimmuno-precipitation assay (RIPA) lysis buffer (Sigma-Aldrich, St Louis, MO, USA). Protein concentrations were determined using a bicinchoninic acid assay (BCA; ThermoFisher, MA, USA). Thirty micrograms of each protein lysate was added to each lane and resolved using sodium dodecyl sulphate-polyacrylamide gel electrophoresis (SDS-PAGE, Sigma Aldrich, St Louis, MO, USA) on 12 or $6 \%$ gels and transferred to polyvinylidene difluoride membranes (Millipore, Bedford, MA, USA). The primary antibodies were diluted in $1 \%(w / v)$ skimmed milk powder in TBS-Tween and incubated overnight at $4{ }^{\circ} \mathrm{C}$. Membranes were then washed and incubated with the appropriate secondary antibodies conjugated with IRDye 800CW (molecular weight $=1162 \mathrm{Da}$ ). Antibody reactivity was detected after exposure in an Odyssey infrared imaging system (LI-COR, Nebraska, USA).All the experiments were repeated three times.

\section{TUNEL assay in cultured fibroblasts}

To evaluate the apoptotic rate of RAPA on fibroblasts, the cells were transferred into a serum-free medium overnight and then pre-treated with or without different concentrations of RAPA for $48 \mathrm{~h}$, the apoptotic rate of 
fibroblasts was analysed using a TdT-mediated dUTPbiotin nick-end labelling (TUNEL) test system (Roche, USA) according to the manufacturer's instructions. Following staining, the apoptotic features of cell death were examined via fluorescence microscopy. The obtained images were merged and analysed using Image J software. The percentage of TUNEL-positive cells was defined as the number of TUNEL-stained cells divided by the number of DAPI-stained cells. The cells were counted by a naive observer.

\section{Statistical analysis}

The statistical analysis was performed with SPSS software (version 19.0). The results of the data were expressed as the means \pm standard deviation. $P$ values $<0.05$ were considered statistically significant.

\section{Results}

\section{Macroscopic assessment of epidural fibrosis}

The surgery was well tolerated by all rats, without the occurrence of wound infection, neurological deficits or cerebrospinal leaks. The results of macroscopic observation indicated that soft or weak scar adhesion was found in the $0.2 \mathrm{mg} / \mathrm{ml}$ RAPA group. Moderate scar adhesion was seen in the $0.1 \mathrm{mg} / \mathrm{ml}$ RAPA group; the tissues could be dissected by manual traction with less bleeding. However, severe epidural adhesions were observed in both the $0.05 \mathrm{mg} / \mathrm{ml} \mathrm{RAPA}$ group and control group; dissection of the scar tissue was difficult and was accompanied by bleeding and disruption of the dura mater. The levels of epidural fibrosis were evaluated according to the Rydell classification, and the results are shown in Table 1.

\section{Histological analysis}

The typical images of HE staining and masson staining of epidural scar tissues at L1-L2 levels were shown in Figs. 1 and 2, respectively. In both the control group and the $0.05 \mathrm{mg} / \mathrm{ml}$ RAPA group, dense epidural scar tissue and compact collagen tissues were found in the laminectomy sites, and the scar tissues were widely adhered to the dura mater and dorsal muscle (Figs. $1 \mathrm{~d}$ and $2 \mathrm{~d}$;

Table 1 The grade of epidural scar adhesion through macroscopic was evaluated in rats according to the Rydell standard

\begin{tabular}{lllll}
\hline Group & Grade & & & \\
\cline { 2 - 5 } & 0 & 1 & 0 & 3 \\
\hline Saline & 0 & 0 & 1 & 4 \\
$0.05 \mathrm{mg} / \mathrm{ml}$ & 0 & 0 & 1 & 0 \\
$0.1 \mathrm{mg} / \mathrm{ml}$ & 0 & 3 & 0 & 0 \\
$0.2 \mathrm{mg} / \mathrm{ml}$ & 3 & 1 & 0
\end{tabular}

Four rats were randomly selected from the RAPA-treated groups of different concentrations and saline group

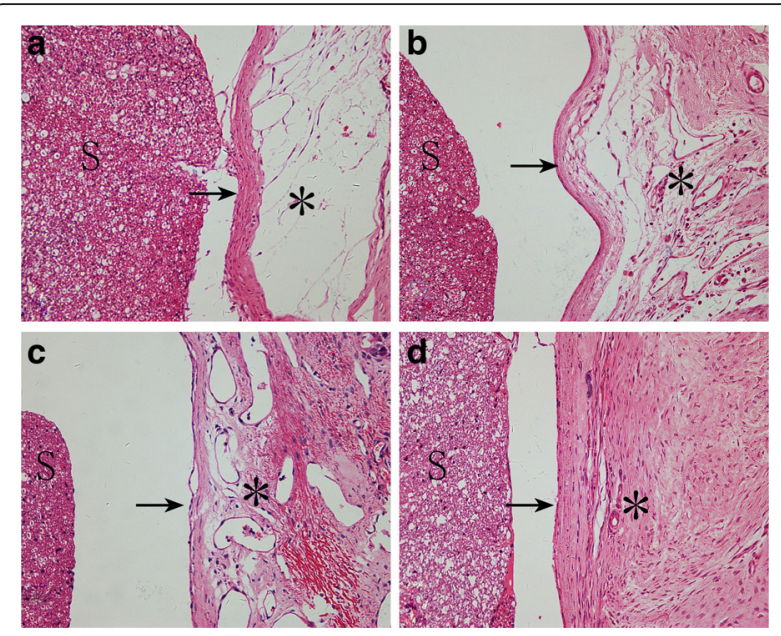

Fig. 1 Photomicrographs of the epidural adhesions at the laminectomy sites from groups treated with $0.2 \mathrm{mg} / \mathrm{ml} \operatorname{RAPA}(\mathbf{a}), 0.1 \mathrm{mg} / \mathrm{ml}$ RAPA (b), $0.05 \mathrm{mg} / \mathrm{ml}$ RAPA (c) and the control group (d). Loose scar tissues (asterisk) with little adherence to the dura mater (arrow) were found in the $0.2 \mathrm{mg} / \mathrm{ml}$ RAPA group (a). Moderate scar tissues (asterisk) were found in the $0.1 \mathrm{mg} / \mathrm{ml}$ RAPA group (b). However, dense scar tissues (asterisks) adhered to the dura mater (arrow) were found in the $0.05 \mathrm{mg} / \mathrm{ml}$ RAPA (c) group and the control group (d). "S" represents the spinal cord. The sections were stained with haematoxylin-eosin. The magnification was $\times 200$

Figs. 1c and 2c). Moderate epidural scar adhesion and collagen tissues were found in the $0.1 \mathrm{mg} / \mathrm{ml}$ RAPA group (Figs. $1 \mathrm{~b}$ and $2 \mathrm{~b}$ ). However, loose scar adhesion and collagen tissues were formed in the $0.2 \mathrm{mg} / \mathrm{ml}$ RAPA group (Figs. 1a and 2a).

\section{Hydroxyproline content analysis}

The hydroxyproline content of epidural scar tissue is shown in Fig. 3. The hydroxyproline content of the $0.2 \mathrm{mg} / \mathrm{ml}$ RAPA group was $33.08 \pm 2.23 \mu \mathrm{g} / \mathrm{mg}$, which was significantly lower than those of the $0.1 \mathrm{mg} / \mathrm{ml}$ RAPA group $(43.39 \pm 2.01 \mu \mathrm{g} / \mathrm{mg})$, the $0.05 \mathrm{mg} / \mathrm{ml}$ RAPA group $(55.08 \pm 1.41 \mu \mathrm{g} / \mathrm{mg})$ and the control group $(58.14 \pm 3.19 \mu \mathrm{g} / \mathrm{mg}) \quad(\# p<0.05)$. The hydroxyproline content of the $0.1 \mathrm{mg} / \mathrm{ml}$ RAPA group was also lower than those of the $0.05 \mathrm{mg} / \mathrm{ml}$ RAPA group and the control group ( $p<0.05)$. However, there was no significant difference between the $0.05 \mathrm{mg} / \mathrm{ml}$ RAPA group and the control group $(p=0.203)$.

\section{Effect of RAPA on fibroblasts in epidural scar tissues}

The fibroblasts of epidural scar tissue and fibroblast counts in each group are shown in Figs. 4 and 5, respectively. The fibroblast counts were $19 \pm 2.65$ in the $0.2 \mathrm{mg} /$ $\mathrm{ml}$ RAPA group, $34.67 \pm 2.52$ in the $0.1 \mathrm{mg} / \mathrm{ml}$ RAPA group, and $50.33 \pm 2.08$ in the $0.05 \mathrm{mg} / \mathrm{ml}$ RAPA group. The $0.2 \mathrm{mg} / \mathrm{ml}$ RAPA group and the $0.1 \mathrm{mg} / \mathrm{ml} \mathrm{RAPA}$ 


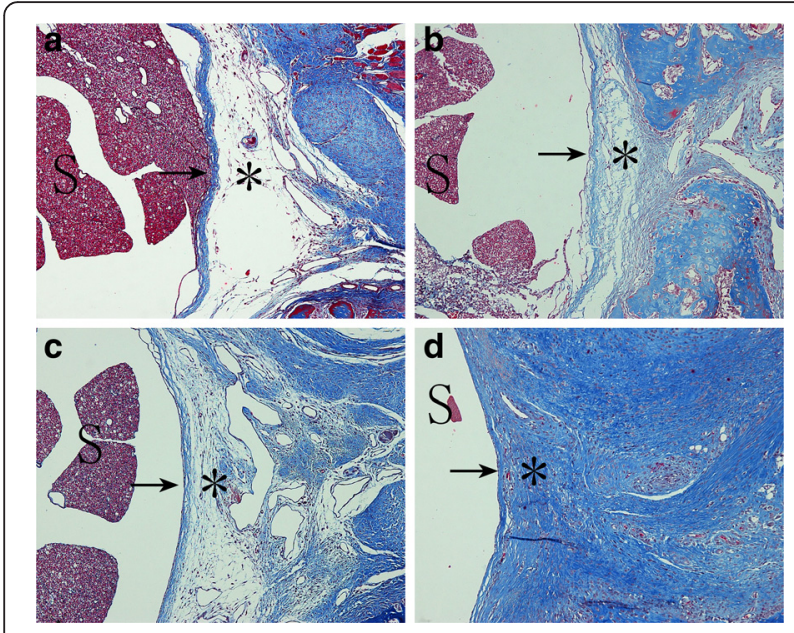

Fig. 2 The effect of RAPA on collagen density in epidural adhesion issues in the laminectomy sites in groups treated with $0.2 \mathrm{mg} / \mathrm{ml}$ RAPA (a), $0.1 \mathrm{mg} / \mathrm{ml}$ RAPA (b), $0.05 \mathrm{mg} / \mathrm{ml}$ RAPA (c) or the control group (d). Collagen tissue is shown in blue because the sections are stained with Masson's trichrome. The density of collagen in the sections from the $0.2 \mathrm{mg} / \mathrm{ml}$ RAPA-treated group (a) was clearly lower than that in tissue samples from the $0.1 \mathrm{mg} / \mathrm{ml}$ RAPA (b) and $0.05 \mathrm{mg} / \mathrm{ml}$ RAPA (c) groups and the control group (d). "S" represents the spinal cord. "**" represents the scar adhesion area of epidural. The sections were stained with masson. The magnification was $\times 100$

group showed significantly lower fibroblast counts than the control group $(54.67 \pm 3.21) \quad(" p<0.05)$, but there was no significant difference between the $0.05 \mathrm{mg} / \mathrm{ml}$ RAPA group and the control group $(p=0.122)$. The number of fibroblasts in the $0.2 \mathrm{mg} / \mathrm{ml}$ RAPA groups was also significantly lower than those of the other RAPA groups $(\# p<0.05)$.

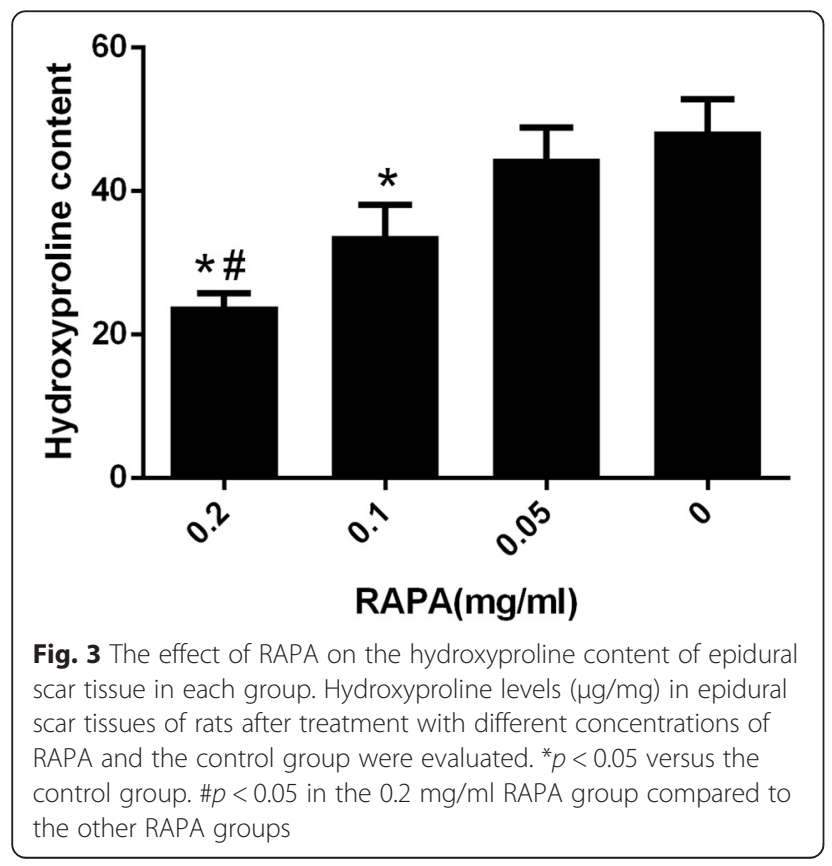

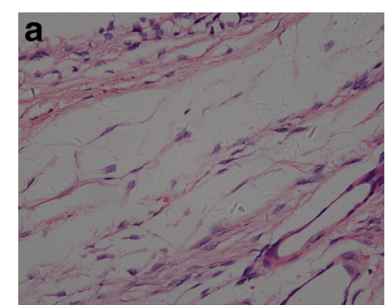
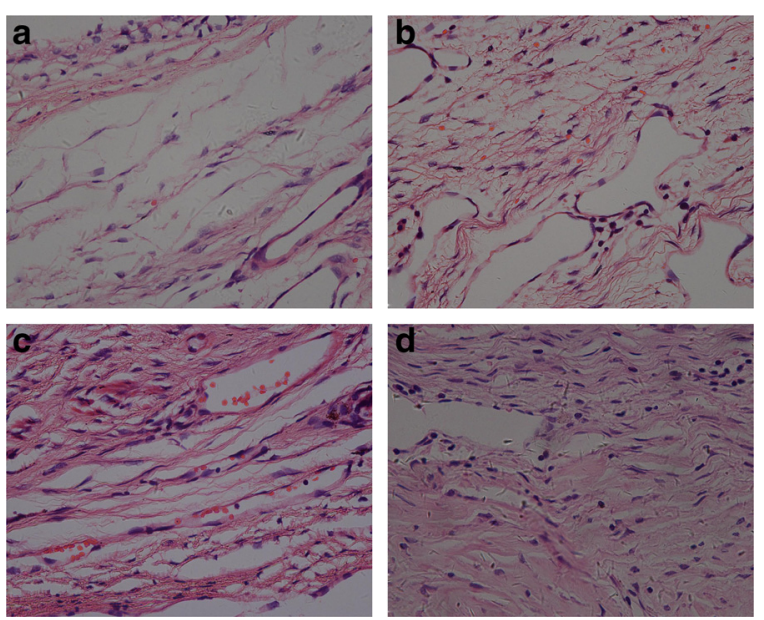

Fig. 4 Histological observation of fibroblasts in the epidural scar tissue of the laminectomy defect areas in groups treated with RAPA of $0.2 \mathrm{mg} / \mathrm{ml}$ (a), $0.1 \mathrm{mg} / \mathrm{ml}$ (b), $0.05 \mathrm{mg} / \mathrm{ml}$ (c) or the control group(d). The number of fibroblasts in the $0.2 \mathrm{mg} / \mathrm{ml}$ RAPA group and $0.1 \mathrm{mg} / \mathrm{ml}$ RAPA group was lower than in the control group, but there was no significant difference between the $0.05 \mathrm{mg} / \mathrm{ml}$ RAPA group and control group. The fibroblast count in the $0.2 \mathrm{mg} /$ $\mathrm{ml}$ RAPA group was also lower than those of the other RAPA groups. The sections were stained with haematoxylin-eosin and the magnification is $\times 400$

\section{Effects of RAPA on the proliferation and apoptosis of fibroblasts}

As shown in Fig. 6, after fibroblasts were transfered into serum-free medium overnight and treated with different concentrations of RAPA $(0,0.01,0.1$, and $1 \mu \mathrm{g} / \mathrm{ml})$ for $48 \mathrm{~h}$, the proliferation of fibroblasts was clearly inhibited. The number of fibroblasts decreased with increasing doses of RAPA.

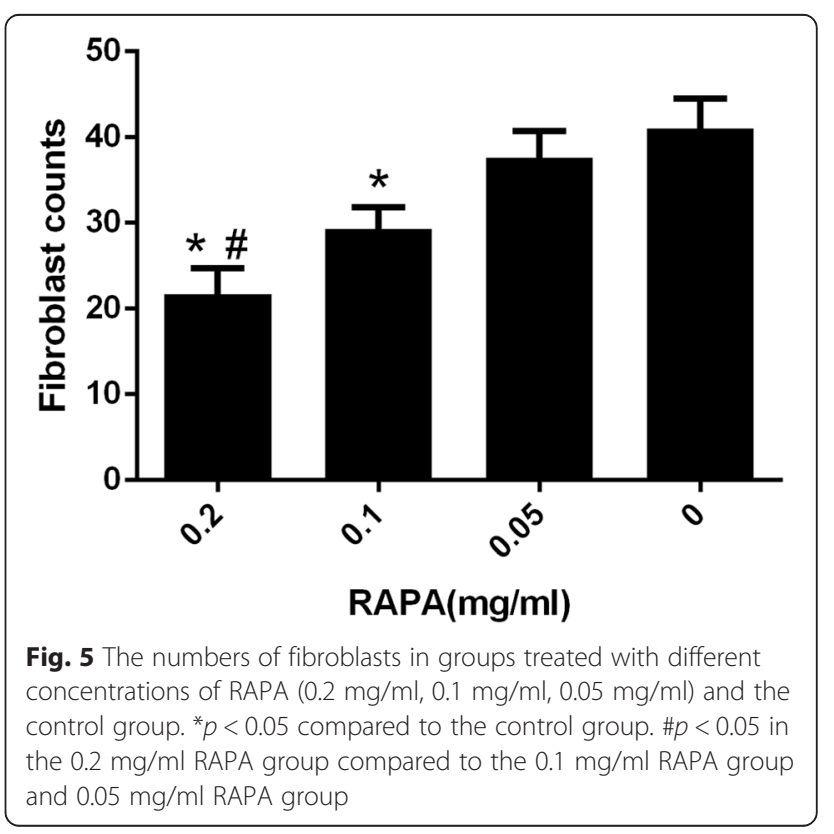




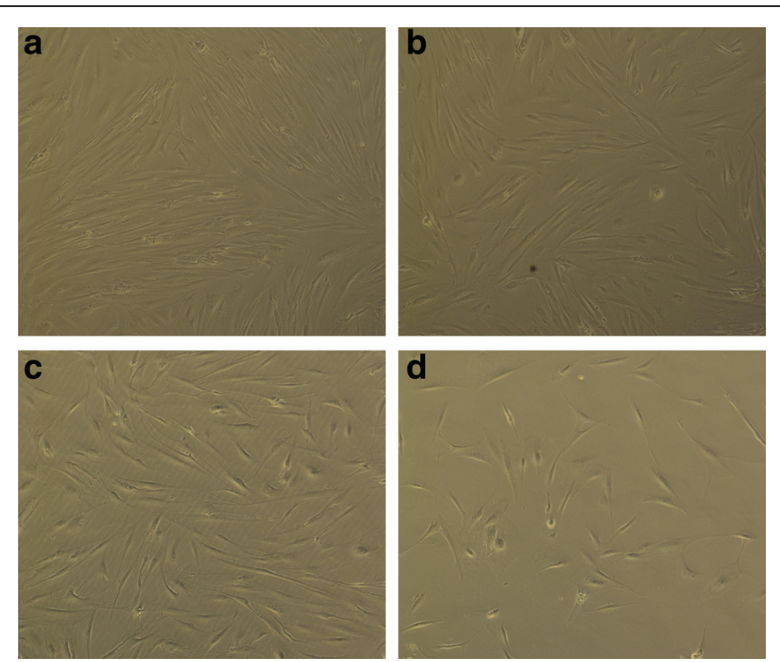

Fig. 6 After fibroblasts were cultured with different concentrations of RAPA $(0.01 \mu \mathrm{g} / \mathrm{ml}(\mathbf{b}), 0.1 \mu \mathrm{g} / \mathrm{ml}(\mathbf{c}), 1 \mu \mathrm{g} / \mathrm{ml}$ (d)) or control (a) for $48 \mathrm{~h}$, the number of cells and cellular morphology were observed under a light microscope. The magnification was $\times 400$

To evaluate the effect of RAPA on the apoptosis of fibroblasts, western blotting was used to determine the expression of the pro-apoptotic proteins cleaved-PARP and Bax and the anti-apoptotic protein Bcl- 2 after fibroblasts were treated with different concentrations of RAPA. With increasing doses of RAPA, the expression levels of cleaved-PARP and Bax increased. However, the expression level of the anti-apoptotic protein Bcl-2 decreased. The results are shown in Fig. 7.

As shown in Fig. 8, the results of the TUNEL assay indicated that few apoptotic fibroblasts were found in the control group. After fibroblasts were treated with different concentrations of RAPA, the number of apoptotic fibroblasts increased. As shown in Fig. 9, compared with those of the control group, the rates of TUNEL-positive cells increased significantly in the fibroblasts of RAPAtreated groups $(" p<0.05)$.

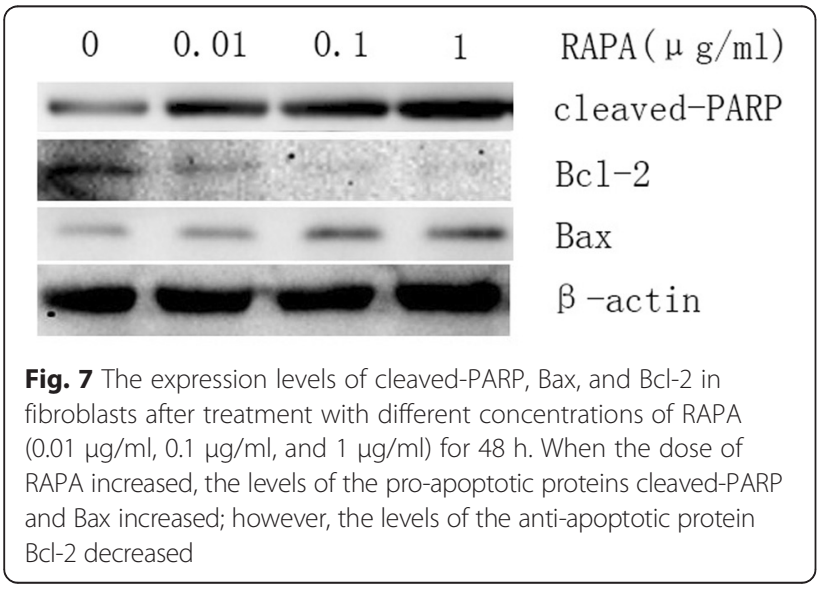

\section{Discussion}

Currently, the exact mechanisms that underlie the development of epidural fibrosis after laminectomy are still uncertain. It has been found that immune and inflammatory reactions play key roles in the formation of epidural fibrosis [33, 34]. After being stimulated by various immune cytokines, fibroblasts tend to proliferate extensively, produce collagen, and release extracellular matrix, which ultimately results in the formation of epidural scar adhesion. Excessive scar tissues tend to adhere to the dura mater or nerve roots in the vertebral canal, thus resulting in nerve root entrapment and limited nerve root mobility. Therefore, pharmaceutical agents that inhibit immune and inflammatory reactions and thus inhibit the proliferation of fibroblasts may be effective in reducing epidural scar adhesion.

RAPA is a new type of immunosuppressive drug characterized by a better clinical effect, low toxicity, and no renal toxicity (Fig. 9). Currently, RAPA is widely used to prevent the acute rejection of allograft transplants and suppress tumour growth [35, 36]. Many studies have shown that RAPA has anti-fibrosis properties. It has been found that 0.01 to $1 \mu \mathrm{g} / \mathrm{ml}$ RAPA inhibits the expression of MMP-1 and collagen in fibroblasts [37]. RAPA also suppresses the proliferation of fibroblasts. Additionally, the placement of a biodegradable rapamycin-eluting nano-fibre membranecovered metal stent reduces fibroblast proliferation in experimental strictures in a canine model [38].

In this study, we cultured fibroblasts from the epidural scar tissues of rats after laminectomy and exposed the cells to various concentrations of RAPA. After fibroblasts were cultured with different concentrations of RAPA $(0,0.01,0.1$, and $1 \mu \mathrm{g} / \mathrm{ml})$ for $48 \mathrm{~h}$, the proliferation of fibroblasts was markedly inhibited. The number of fibroblasts decreased with increases in the concentration of RAPA. The western blotting results indicated that RAPA promoted the expression of pro-apoptotic proteins, such as Bax and cleaved-PARP, whereas it inhibited the expression of the antiapoptotic protein $\mathrm{Bcl}-2$ in fibroblasts. The results of the TUNEL assay indicated that RAPA promoted the apoptosis of fibroblasts.

Next, we constructed a laminectomy model in rats and treated them with different concentrations of RAPA, chosen on the basis of previous studies [37, 39]. We found that the local application of RAPA inhibited fibroblast proliferation in epidural scar tissues and reduced epidural fibrosis in rats. We evaluated the effect of RAPA in reducing epidural fibrosis by using several methods, including macroscopic assessment of epidural fibrosis, evaluation of hydroxyproline content, histological analysis, and fibroblast counting. The results indicated that the local 


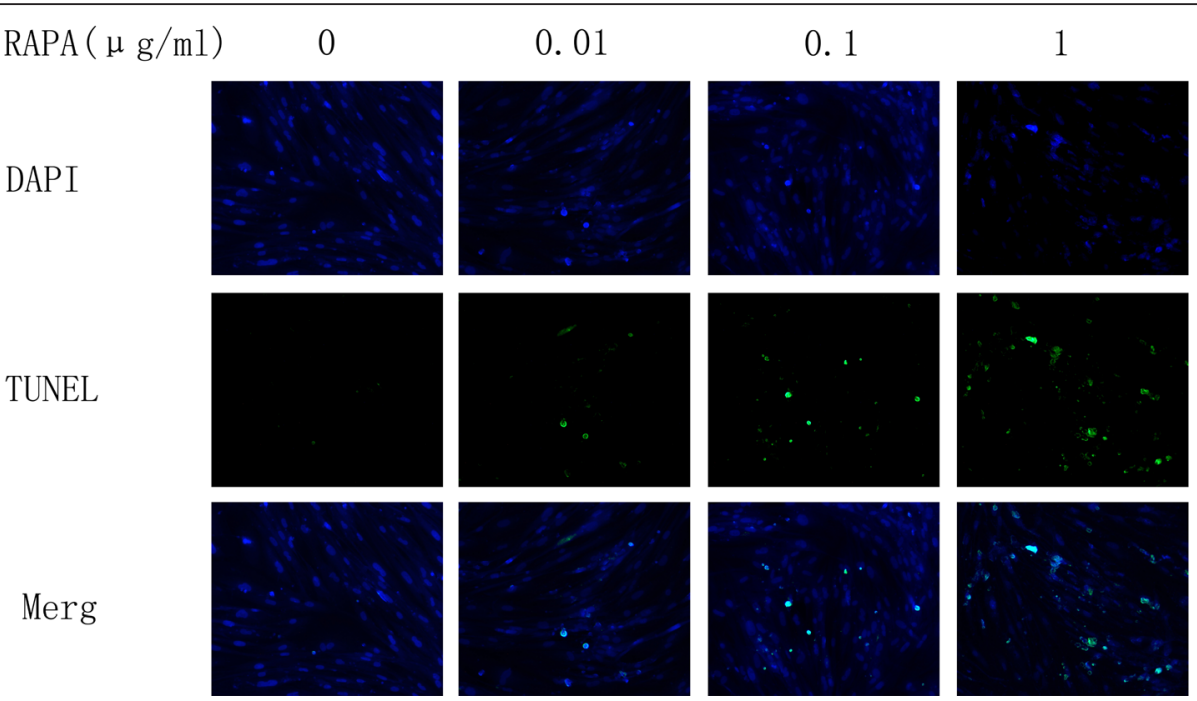

Fig. 8 The results of TUNEL staining after fibroblasts were treated with different concentrations of RAPA $(0.01 \mu \mathrm{g} / \mathrm{ml}, 0.1 \mu \mathrm{g} / \mathrm{ml}$, and $1 \mu \mathrm{g} / \mathrm{ml})$ for $48 \mathrm{~h}$ are shown. The nuclei of fibroblasts were stained with DAPI. After TUNEL staining, the nuclei of apoptotic fibroblasts were green. When the dose of RAPA increased, the number of apoptotic nuclei increased. The images were observed using fluorescence microscopy. The magnification is $\times 400$

application of RAPA inhibited fibroblast proliferation and reduced epidural fibrosis in a rat laminectomy model without any signs of wound infection, neurological deficits or cerebrospinal leakage. Additionally, $0.2 \mathrm{mg} / \mathrm{ml}$ RAPA exhibited better effectiveness than did lower concentrations of RAPA. Different concentrations of RAPA reduced epidural adhesion in a dosedependent manner, except for the $0.05 \mathrm{mg} / \mathrm{ml} \mathrm{RAPA}$ group, which showed no difference compared with the control group.

The results of this and previous studies show that RAPA can reduce epidural scar adhesion. RAPA prevents the progression of the cell cycle from G1 to $S$ phases in T-lymphocytes and other cell types through

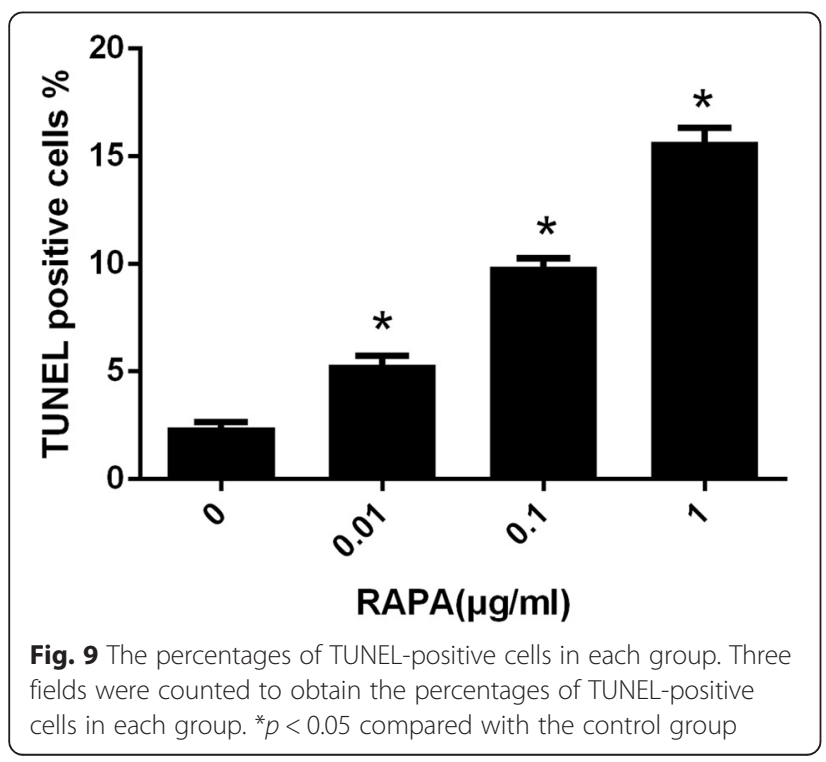

various signal transduction pathways. It also inhibits the proliferation of immune cells, including fibroblasts. RAPA binds to immunophilin FKBP12, which blocks the nuclear factor of activated T-cells from entering the nucleus, reduces the production of cytokines such as IL-2 and alleviates the immune reaction [40]. As the number of inflammatory cytokines decreases, the number of fibroblasts decreases. Additionally, RAPA inhibits the expression of $\mathrm{Bcl}-2$ in Tlymphocytes and other cell types, including fibroblasts; thus, RAPA promotes fibroblast apoptosis and accordingly decreases epidural fibrosis after laminectomy [41].

Considering these results, we concluded that the local application of RAPA may be an innovative and safe treatment for reducing epidural fibrosis. To accomplish this effect, RAPA affects the activity of fibroblasts after the immune reaction is alleviated. The present study is a preliminary assessment of the effect of RAPA on decreasing epidural fibrosis, using histological and histomorphometric analysis. A higher dosage of RAPA may produce better results, and more in-depth research on its mechanisms is still needed in the future.

\section{Conclusions}

The local application of RAPA can reduce epidural fibrosis after laminectomy by inhibiting the proliferation of fibroblasts, stimulating their apoptosis, and decreasing collagen synthesis. This protocol may be used in new clinical treatment strategies to reduce epidural fibrosis after laminectomy. 


\section{Ethics approval}

All animals received care according to the principles of Laboratory Animal Care and international recommendations, and the experimental protocol was approved by the Animal Care and Research Committee of Central South University, China.

\section{Abbreviations}

HE: haematoxylin and eosin; RAPA: rapamycin.

\section{Competing interests}

The authors declare that they have no competing interests.

\section{Authors' contributions}

YS and SZ performed the whole experiments and were responsible for the data and drafting the article. $X \mathrm{~L}, \mathrm{LY}$, and JW designed the study and contributed to the preparation of the manuscript. DW, HC, JD, and $J H$ helped in the performance of animal surgeries and the interpretation of data. All authors read and approved the final manuscript.

\section{Acknowledgements}

We would like to express our great appreciation to all the workers of the Pathology laboratory of Yangzhou University.

\section{Funding}

This work was supported by grants from the National Natural Science Foundation of China (Grants\#81271994, 81301550, 81371971 and 81501870).

\section{Author details}

${ }^{1}$ Department of Orthopedics, Clinical medical college of Yangzhou University, Nantong West Road 98, Yangzhou, Jiangsu 225001, China. ${ }^{2}$ Department of Orthopedics, Xiangya Second Hospital, Central South University, Changsha, Hunan 410012, China. ${ }^{3}$ Orthopedics Institute, Subei People's Hospital of Jiangsu Province, Yangzhou, Jiangsu 225001, China.

Received: 29 January 2016 Accepted: 17 April 2016

\section{Published online: 06 May 2016}

\section{References}

1. Cooper RG, Mitchell WS, Illingworth KJ, Forbes WS, Gillespie JE, Jayson MI. The role of epidural fibrosis and defective fibrinolysis in the persistence of postlaminectomy back pain. Spine. 1991;16(16):1044-8.

2. Bosscher HA, Heavner JE. Incidence and severity of epidural fibrosis after back surgery: an endoscopic study. Pain Pract. 2010;10(10):18-24.

3. Ross JS, Robertson JT, Frederickson RC, Petrie JL, Obuchowski N, Modic MT, et al. Association between peridural scar and recurrent radicular pain after lumbar discectomy: magnetic resonance evaluation. Neurosurgery. 1996; 38(4):855-63.

4. Cruccu G, Aziz TZ, Garcia-Larrea L, Hansson P, Jensen TS, Lefaucheur J, et al. EFNS guidelines on neurostimulation therapy for neuropathic pain. Eur Nerol. 2007;14(9):952-70.

5. BENOIST M, FICAT C, BARAF P, CAUCHOIX J. Postoperative lumbar epiduroarachnoiditis: diagnostic and therapeutic aspects. Spine. 1980;5(5):432-6.

6. Liu S, Boutrand JP, Bittoun J, Tadie M. A collagen-based sealant to prevent in vivo reformation of epidural scar adhesions in an adult rat laminectomy model. J Neurosurg Spine. 2002;97(1):69-74

7. Rodgers KE, Robertson JT, Espinoza T, Oppelt W, Cortese S, Dizerega GS, et al. Reduction of epidural fibrosis in lumbar surgery with oxiplex adhesion barriers of carboxymethylcellulose and polyethylene oxide. Spin J. 2003;3(4):277-83.

8. Cekinmez M, Sen O, Atalay B, Erdogan B, Bavbek M, Caner H, et al. Effects of methyl prednisolone acetate, fibrin glue and combination of methyl prednisolone acetate and fibrin glue in prevention of epidural fibrosis in a rat model. Neurol Res. 2010;32(7):700-5.

9. Li X, Chen L, Lin H, Cao L, Cheng J, Dong J, et al. Efficacy of poly(D,L-lactic acid-co-glycolic acid)-poly(ethylene glycol)-poly(D,L-lactic acid-co-glycolic acid) thermogel as a barrier to prevent spinal epidural fibrosis in a postlaminectomy rat model. J Spinal Disord Tech. 2014

10. Tao H, Fan $\mathrm{H}$. Implantation of amniotic embrane to reduce postlaminectomy epidural adhesions. Eur Spine J. 2009;18(8):1202-12.
11. Sun $Y$, Wang $L$, Wang $L$, Sun $S$, Cao $X$, Wang $P$, et al. A comparison of the effectiveness of mitomycin $C$ and 5 -fluorouracil in the prevention of peridural adhesion after laminectomy. J Neurosurg Spine. 2007;7(4):423-8.

12. Chao Z, Xiaohong K, Guangzhi N, Zhipin L, Tongjun Q, Feiran C, et al. All-trans retinoic acid prevents epidural fibrosis through $n f-k b$ signaling pathway in post-laminectomy rats. Neuropharmacology. 2014;79:275-81.

13. Kartal Hakan Y, Ferruh G, Merih I, Selma C, Murat D. Mitomycin C, 5fluorouracil, and cyclosporin a prevent epidural fibrosis in an experimental laminectomy model. Eur Spine J. 2007;16(9):1525-30.

14. Sun Y, Ge Y, Fu Y, Yan L, Cai J, Shi K, et al. Mitomycin C induces fibroblasts apoptosis and reduces epidural fibrosis by regulating miR-200b and its targeting of RhoE. Eur J Pharmacol. 2015;765:198-208.

15. Yan L, Li X, Wang J, Sun Y, Wang D, Gu J, et al. Immunomodulatory effectiveness of tacrolimus in preventing epidural scar adhesion after laminectomy in rat model. Eur J Pharmacol. 2013;699(1):194-9.

16. Gan W, Liu P, Wei W. Cell cycle status dictates effectiveness of rapamycin. Cell Cycle. 2015;14(16):2556-7.

17. Guba M, von Breitenbuch P, Steinbauer M, Koehl G, Flegel S, Hornung M, et al. Rapamycin inhibits primary and metastatic tumor growth by antiangiogenesis: involvement of vascular endothelial growth factor. Nat Med. 2002;8(2):128-35.

18. Heitman J. On the discovery of TOR as the target of rapamycin. Plos Pathog 2015;11(11):e1005245

19. Kwon YS, Kim JC. Inhibition of corneal neovascularization by rapamycin. Exp Mol Med. 2006;38(2):173-9.

20. Ming D, Xin W, Jie L, Yu-Xia Z, Xing-Long C, Ke-Qiu L, et al. Rapamycin combined with immature dendritic cells attenuates obliterative bronchiolitis in trachea allograft rats by regulating the balance of regulatory and effector t cells. Int Arch Allergy Immunol. 2015;167(3):177-85

21. Bertelmann E, Pleyer U. Immunomodulatory therapy in ophthalmology - is there a place for topical application? Ophthalmologica. 2004;218(6):359-67.

22. Salas-Prato M, Assalian A, Mehdi AZ, Duperr EJ, Thompson P, Brazeau P. Inhibition by rapamycin of PDGF-and bFGF-induced human tenon fibroblast proliferation in vitro. J Glaucoma. 1996:5(1):54-9.

23. Liu H, Zhang Y, Ma H, Zhang C, Fu S. Comparison of posterior capsule opacification in rabbit eyes receiving different administrations of rapamycin Graefes Arch Clin Exp. 2014;252(7):1111-8.

24. Meng $Q$, Guo H, Xiao L, Cui Y, Guo R, Xiao D, et al. mTOR regulates TGF- $\beta 2$ induced epithelial—mesenchymal transition in cultured human lens epithelial cells. Graefes Arch Clin Exp. 2013;251(10):2363-70.

25. Ayumi Y, Koichi Y, Asako Y, Yohei I, Kazuhiro K, Fumihide O, et al. Treatment with rapamycin prevents fibrosis in tight-skin and bleomycin-induced mouse models of systemic sclerosis. Arthritis Rheum. 2010;62(8):2476-87.

26. Gao $Y, X u$ X, Ding K, Liang $Y$, Jiang D, Dai H. Rapamycin inhibits transforming growth factor $\beta 1$-induced fibrogenesis in primary human lung fibroblasts. Yonsei Med J. 2013;54(2):437-44

27. Namba DR, Ma G, Samad I, Ding D, Pandian V, Powell JD, et al. Rapamycin inhibits human laryngotracheal stenosis-derived fibroblast proliferation, metabolism, and function in vitro. Otolaryngol Head Neck Surg.2015;152(5):881-8.

28. Lee J, Stenzel W, Ebel H, Wedekind C, Ernestus R, Klug N. Mitomycin C in preventing spinal epidural fibrosis in a laminectomy model in rats. J Neurosurg Spine. 2004;100(1):52-5.

29. Lee J, Stenzel W, Ebel H, Wedekind C, Ernestus R, Klug N. The role of mitomycin $\mathrm{c}$ in reducing recurrence of epidural fibrosis after repeated operation in a laminectomy model in rats. J Neurosurg Spine. 2006:4(4): 329-33.

30. Rydell NW, Butler J, Balazs EA, et al. Hyaluronic acid in synovial fluid. VI. Effect of intra-articular injection of hyaluronic acid on the clinical symptoms of arthritis in track horses. Acta Vet Scand. 1970;11:139-55.

31. Woessner JF. The determination of hydroxyproline in tissue and protein samples containing small proportions of this imino acid. Arch Biochem Biophys. 1961:93(2):440-7.

32. Fukui N, Tashiro T, Hiraoka H, Oda H, Nakamura K. Adhesion formation can be reduced by the suppression of transforming growth (factor-beta 1) activity. J Orthop Res. 2000;18(2):212.

33. Zhang C, Kong X, Liu C, Liang Z, Zhao H, Tong W, et al. ERK2 small interfering RNAs prevent epidural fibrosis via the efficient inhibition of collagen expression and inflammation in laminectomy rats. Biochem Biophys Res Commun. 2014;444(3):395-400 
34. Emmez H, Börcek AÖ, Durdağ E, Uyar PG, Kaymaz M, Aykol S. Immunomodulatory effectiveness of azithromycin in prevention of postlaminectomy epidural fibrosis. Neurol Res. 2011;33(4):344-8.

35. Weber T, Abendroth $\mathrm{D}$, Schelzig H. Rapamycin rescue therapy in patients after kidney transplantation: first clinical experience. Transpl Int. 2005;18(2):151-6.

36. Paola P, Michele R, Barbara I, Giovanni S, Antonio S, Antonia L, et al. Rapamycin inhibits pai-1 expression and reduces interstitial fibrosis and glomerulosclerosis in chronic allograft nephropathy. Transplantation. 2008; 85(1):125-34.

37. Poulalhon N, Farge D, Roos N, Tacheau C, Neuzillet C, Michel L, et al. Modulation of collagen and MMP-1 gene expression in fibroblasts by the immunosuppressive drug rapamycin a Direct role as an antifibrotic agent? J Biol Chem. 2006;281(44):33045-52.

38. Zhu YQ, Cui WG, Cheng YS, Chang J, Chen NW, Yan L, et al. Biodegradable rapamycin-eluting nano-fiber membrane-covered metal stent placement to reduce fibroblast proliferation in experimental stricture in a canine model. Endoscopy. 2013:45(6):458-68.

39. Schachner T, Zou Y, Oberhuber A, Tzankov A, Mairinger T, Laufer GUN, et al. Local application of rapamycin inhibits neointimal hyperplasia in experimental vein grafts. Ann Thorac Surg. 2004;77(5):1580-5.

40. Assmann T, Homey B, Ruzicka T. Applications of tacrolimus for the treatment of skin disorders. Immunopharmacology. 2000:47(2):203-13.

41. Shi Y, Frankel A, Radvanyi LG, Penn LZ, Miller RG, Mills GB. Rapamycin enhances apoptosis and increases sensitivity to cisplatin in vitro. Cancer Res. 1995;55(9):1982-8

\section{Submit your next manuscript to BioMed Central and we will help you at every step:}

- We accept pre-submission inquiries

- Our selector tool helps you to find the most relevant journal

- We provide round the clock customer support

- Convenient online submission

- Thorough peer review

- Inclusion in PubMed and all major indexing services

- Maximum visibility for your research

Submit your manuscript at www.biomedcentral.com/submit

) Biomed Central 